\title{
INSTITUIÇÕES TOTAIS E A QUESTÃO ASILAR: uma abordagem compreensiva
}

\author{
Lucas Graeff*
}

\section{Resumo}

Este é um estudo antropológico sobre o envelhecimento em contexto asilar, resultado da pesquisa etnográfica desenvolvida entre agosto de 2004 e dezembro de 2005 no Asilo Padre Cacique, em Porto Alegre - RS. Propõe-se a discussão da Teoria das Instituições Totais a partir da análise das condições de vida e do processo de envelhecimento dos moradores daquela instituição, com a finalidade de conhecer suas práticas, interpretar seus tempos vividos e compreender de que maneira esses velhos pensam suas experiências e sua velhice no cotidiano asilar.

Palavras-chave: Instituições. Cotidiano. Velhice.

\section{Introdução}

Ao contrário de vários artigos sobre a questão do envelhecimento populacional no Brasil e de todos os autores que sublinham a construção social do problema da velhice e da Terceira Idade aqui e em outros países do mundo, não vou apresentar dados do Instituto Brasileiro de Geografia e Estatística (IBGE) ou descrever as diversas maneiras de como tal "problema social" foi ou está sendo construído. Opto por abrir este artigo à partir de uma questão: por definição, pode-se afirmar que todo asilo é uma instituição total? Faço referência, naturalmente, ao texto clássico do interacionismo simbólico intitulado Manicômios, Prisões e Conventos, escrito por Erving Goffman (1974). Um livro que vem servindo de base para boa parte das análises sobre o processo de institucionalização no Brasil.

Mesmo sem jamais haver colocado um pé em um asilo e em aceitando por definição seu caráter totalitário, a teoria de Goffman me permitiria afirmar que tais lugares são espaços sociais fechados, onde

\footnotetext{
* Psicólogo e Antropólogo. Mestre em Antropologia pela Universidade Federal do Rio Grande do Su (UFRGS). Doutorando em Antropologia pela Universidade de Paris V - René Descartes.

E-mail: lucasgraeff@gmail.com
} 
regras minuciosas são colocadas em prática no sentido de limitar e homogeneizar as atividades diárias dos internos. Esse esforço de redução sistemática da autonomia individual levaria, gradativamente, à "mortificação do eu" (GOFFMAN, 1974), ou seja: a "economia de ação do internado" , como descreve o autor, acaba se tornando cada vez mais restrita. Enquanto ator social, o conjunto de papéis com os quais um idoso asilado poderia contar em seu "eu" torna-se restrita na medida em que a instituição é menos aberta para o mundo exterior.

O que me parece mais grave no parágrafo anterior não é o numero de "fatos" típicos de um asilo que se pode encontrar através da teoria interacionista, mas a própria possibilidade de analisar a condição asilar sem jamais conhecer o cotidiano de uma instituição ou as pessoas que ali habitam. Além disso, na medida em que um pesquisador ou alguém curioso se interessa pela questão asilar e lê Manicômios, Prisões e Conventos (GOFFMAN, 1974), ele parece encontrar ali todas as interpretações possíveis do comportamento desse "eu" institucionalizado, realizadas magistralmente por Goffman (1974) a partir de sua experiência no St. Elizabeth's Hospital, em Washington (EUA). Ao final, mesmo que ele entre em contato com uma centena de "clínicas geriátricas", de "casas de repouso" ou de "lares", se não conseguir se distanciar das proposições interacionistas, ele continuará partindo de uma mesma ficção de origem, uniforme e explicativa - a Teoria das Instituições Totais - para chegar sistematicamente nas mesmas conclusões do autor canadense.

Por ser partidário de uma abordagem compreensiva das ciências humanas (DILTHEY, 1992; GADAMER, 1997; GEERTZ, 1989; OLIVEIRA, 2003), prefiro suspender temporariamente as explicações totalizantes e buscar a constituição de um mundo compartilhado, a partir do qual espero criar ou aprofundar uma perspectiva sobre um determinado fenômeno social. Foi o que procurei fazer durante a pesquisa etnográfica desenvolvida entre agosto de 2004 e dezembro de 2005 no Asilo Padre Cacique, em Porto Alegre (GRAEFF, 2005).

Durante os dezesseis meses de idas e vindas à instituição, interessei-me por como as pessoas que viviam ali ${ }^{1}$ compreendiam a experiência de envelhecer em contexto asilar, levando em consideração a

Infelizmente, não procurei aprofundar a relação com os funcionários e voluntários durante aquela pesquisa, o que eu considero fundamental para uma compreensão mais global da experiência de envelhecer no asilo. 
ruptura com grupos e espaços sociais de referência; o afastamento ou a morte de parentes, amigos ou vizinhos; a perda da posição na hierarquia social, resultado de projetos familiares ou individuais mal sucedidos; as modificações físicas e o estranhamento do próprio corpo; enfim, fatos concretos e representações da velhice institucionalizada que faziam parte do contexto cultural do Asilo Padre Cacique à época da pesquisa.

O objetivo deste artigo é, portanto, descrever e sistematizar a diversidade dos encontros que pude realizar com os moradores do Asilo Padre Cacique durante o tempo vivido com eles no decorrer do trabalho etnográfico. Uma diversidade que deve servir de contra-ponto às explicações fáceis - e, por vezes, gratuitas - de quem percebe o processo de asilamento através de uma perspectiva unilateral fundada no interacionismo simbólico. Vale lembrar, porém, que a compreensão da questão asilar aqui não inviabiliza necessariamente a Teoria das Instituições Totais - ainda que o contrário tenha o costume de acontecer.

Para a realização da etnografia, foi-me necessária a permanência diária no Asilo. Nos primeiros meses, privilegiei a escuta de conversas fortuitas entre os internos e funcionários, bem como a observação das maneiras de ocupar ou habitar os espaços institucionais. Interessei-me, igualmente, pelas trajetórias sociais dos idosos e idosas e, a partir de entrevistas não-diretivas realizadas com três homens e três mulheres, procurei compreender a organização da identidade social no Asilo através da narrativa. Durante a pesquisa, percebi a importância dos armários enquanto espaços de intimidade e de manutenção ou transformação do "eu", o que me levou a realizar novas entrevistas nesse micro-contexto. Vale lembrar que utilizei técnicas audiovisuais durante toda a etnografia, especialmente a fotografia, a qual ajudou a estabelecer um sistema de trocas e a negociar a minha identidade de pesquisador ${ }^{2}$. As três partes deste artigo estão relacionadas a essas diferentes camadas da experiência etnográfica.

\section{O Mundo da Velhice no Asilo Padre Cacique}

A decisão pelo asilamento configura um drama social (TURNER, 1982). Para além da ruptura com as redes sociais de referência e

2 Os limites deste artigo não me permitem discutir com profundidade o uso de técnicas audiovisuais em Antropologia, como procurei fazer em minha dissertação de mestrado (GRAEFF, 2005).. 
os grupos de pertencimento, como a família, a vinda para o asilo convoca novas reflexões sobre a velhice enquanto problema social e sobre os riscos próprios do envelhecimento. As doenças, especialmente a senilidade, eventualmente tornam-se o horizonte dessas reflexões: a institucionalização costuma ser justificada como a alternativa viável para a manutenção da integridade física do velho. Mas vir para o Asilo Padre Cacique também pode ser definido como um projeto. Ao invés de permanecer no espaço doméstico ${ }^{3}$, ocupando uma posição ambígua na família, o idoso renuncia a ele e opta por recuperar parcialmente ou totalmente sua autonomia no espaço asilar.

Independente dos motivos da decisão, os primeiros tempos de institucionalização são marcados por um processo de ajustamento, durante o qual as ambigüidades e o estigma da nova condição são vividos junto a uma experiência de aprendizado de novos padrões culturais. Tomar parte na cultura asilar, de uma maneira geral, significa compreender e incorporar esse conjunto complexo e hierarquizado de maneiras de pensar e agir, que são dados no próprio ritmo das relações estabelecidas em cada espaço social habitado. Uma das facetas da cultura asilar no Asilo Padre Cacique era definida por códigos de distinção/identificação ${ }^{4}$, um conjunto de modelos de comportamento e de controle das emoções, que são gradativamente incorporados quando se entra nesse novo espaço simbólico.

No Asilo, o núcleo organizador desses códigos era a preocupação com o controle das faculdades fisiológicas e mentais: escapar da senilidade, mantendo uma condição digna, parecia ser um grande projeto compartilhado por todos, o qual corria riscos a cada queda, a cada adoecimento e a cada morte. Desde esse núcleo organizador, os códigos poderiam ser apropriados ou reinventados contextualmente, conforme as trajetórias sociais, os espaços habitados e os ritmos de envelhecer no

\footnotetext{
3 O "projeto" de vir morar no Asilo também pode ser constituído por alguém que vive na rua ou por um idoso que mora sozinho ou em condições precárias de existência. Tais possibilidades serão objeto de um artigo futuro.

4 Esses códigos de distinção/identificação se assemelham aos "modelos de auto-controle", propostos por Norbert Elias (1994, p. 201): são gabaritos para a adequação social dos comportamento e das emoções que se tornam cada vez mais automatizado na medida em que avança o processo civilizador, ou seja, o processo de constituição da sociedade ocidental moderna que, segundo o autor, ainda está em curso. Trata-se de uma "[ . . . ] compulsão real que o indivíduo exerce sobre si mesmo, seja como resultado do conhecimento das possíveis conseqüências de seus atos, seja como resultado de gestos correspondentes de adultos que contribuíram para lhe modelar o comportamento desde criança."
} 
Asilo. Pensando com Marshall Sahlins (2004), os códigos de distinção/ identificação podem ser definidos como uma série de repertórios que os velhos praticavam em seu cotidiano - recombinações das categorias culturais disponíveis, que produziam inovações a cada uso e, simultaneamente, eram transmitidas enquanto estruturas de significação.

Esses repertórios nunca foram unívocos. Havia uma grande diferença entre as formas que os homens e mulheres se apropriavam deles no espaço asilar. Algumas mulheres viviam um tensionamento entre o cultivo de novas associações afetivas e a manutenção de espaços de intimidade. Para outras, as relações com voluntários e com a família eram mais valorizadas. O cotidiano do Asilo, no caso das mulheres, também era pautado pela preocupação com o respeito e boa educação. Categorias de acusação, especialmente a da senilidade, estavam sempre em jogo, classificando e organizando os comportamentos. Em algumas situações, brigar com alguém senil poderia implicar na própria estigmatização. De maneira geral, porém, as trocas afetivas com funcionários, voluntários e visitantes, ao contrário, sempre foram índices de sanidade mental.

O corpo é o suporte primário da comunicação social (LE BRETON, 2005). Gestos, roupas, maneiras de se deslocar no espaço; no Asilo, pude perceber uma variedade significativa de formas de andar (com e sem bengala, arrastando ou não os pés no chão, apoiando-se no andador ou em um voluntário, com cadeiras de rodas etc.). Nesse sentido, os ritmos do envelhecer também podiam ser compreendidos através do corpo. Geralmente progressivo - esperava-se, de maneira geral, que as perdas e as doenças fossem gradativas - o tempo cotidiano também poderia se transformar abruptamente, através de um infarto, de uma queda. "A velhice derruba" era uma frase recorrente que os idosos e idosas mencionavam para mim ou entre si.

Frente a essas ambigüidades, o foro íntimo, pautado pelo silêncio e pela solidão, acaba sendo um momento privilegiado de tranqüilidade. Resguardar-se das situações de sociabilidade e dos momentos lúdicos cria um tempo de suspensão, de prudência na aplicação dos modelos de auto-controle. Ao invés de se colocar sistematicamente no fluxo das trocas e da sociabilidade, a reclusão e o silêncio tornam-se não o sinal de uma velhice "passiva", "abandonada", "à espera da morte", mas um momento de afirmação da intimidade. Por que, afinal, sanidade e saúde 
precisariam estar necessariamente ligadas à atividade e ao lazer?

$\mathrm{Na}$ ala feminina, muitos dos conflitos foram disputas por apropriações de espaços, por associações afetivas e, conseqüentemente, por distinção social. Além de evitar brigas com pessoas consideradas senis, era fundamental resolver os conflitos rapidamente e evitar disputas sistemáticas. "Sair por cima" da situação, com respeito e dignidade, indica a "boa educação" . Nessas situações, a mediação de autoridades institucionais foi decisiva para a definição de papéis: afinal, quem estava com a razão? Quem defendeu adequadamente seus espaços ou suas relações afetivas? A intervenção do diretor ou da assistente social podia servir como foro último para a resolução de conflitos.

Os homens também viviam os códigos de distinção/identificação, tramando sentidos em suas vidas apesar das rupturas. Mas com algumas apropriações específicas, como o caráter fantasioso das trajetórias sociais: aproveitando inteligentemente as oportunidades e o espaço potencial de imaginação criado a partir do distanciamento dos grupos de referência - as testemunhas dos tempos vividos - os idosos contavam vantagens, explorando relações com personagens e momentos de prestígio. "Auto-proclamam-se", como diria Guita Debert (1999), geralmente no sentido de reestruturar a identidade social, fragmentada por exclusões sociais sistemáticas: do mercado de trabalho, da posição de autoridade na família, do espaço urbano.

Esse espaço potencial da imaginação era definido relacionalmente a partir de um fato concreto: todos estavam no asilo. E não era uma instituição qualquer, mas o Padre Cacique, asilo considerado por eles como uma das melhores alternativas de institucionalização no Rio Grande do Sul, ao menos para quem não possui as condições sócioeconômicas para escolher uma instituição privada - " aqui não entra qualquer pessoa ", frase repetida por dois dos moradores. Portanto, eles ponderavam a existência de méritos para conseguir uma vaga, mesmo que estivessem ali sem uma "aposentadoria digna" ou "sem o respeito dos filhos." Esses elementos objetivos organizavam as auto-proclamações, as histórias maravilhosas, os sucessos e insucessos narrados.

Azevedo, João e Rui, informantes da pesquisa, me explicaram que as "mentiras" e "fantasias" ocorriam porque "as pessoas vão dando

Refiro-me, aqui, aos depoimentos de Luduvica Dechuta Ploharski e de Lídia Ferreira, moradoras do Asilo à época da pesquisa. 
trela", isto é, na medida em que o contador de histórias não sofria represálias por parte de quem as ouve. Os mentirosos costumam receber apelidos, que podem ou não ser conhecidos por eles: "tem o Búfalo Bill, tem o sete línguas”, diz João. E Rui completa:

[... ] é, o cara diz por aí que fala sete línguas, diz que é primo do Gaúcho da Fronteira ${ }^{6} .$. Além de velho, é mentiroso! Disse que o Gaúcho ficou mal, que não tinha dinheiro prá nada e que levou umas bergamotas ${ }^{7}$ prá ele no hospital. Mas capaz que o Gaúcho da Fronteira não vai ter dinheiro. O cara tá lá no [Hospital] Mãe de Deus, um dos melhores de Porto Alegre... Lá trabalha o Dr. Lucchese, um dos melhores do Estado!

Pode-se dizer que é a verossimilhança que está em jogo nesse tipo de narrativa. Estruturalmente, uma ou duas peripécias são fundamentais para definir uma boa história. É razoável aceitar que alguém já ocupou uma posição de prestígio ou que teve uma carreira bem-sucedida, mas que, em determinado momento inoportuno, tudo se perdeu: a sociedade faliu por causa das oscilações da economia ou pelo sócio mal-intencionado; a morte do patrão de confiança e a conseqüente demissão; o sistema de previdência social que falhou na distribuição do valor correto da aposentadoria; uma doença ou acidente de trabalho que provocou a invalidez. O sucesso depende das relações estabelecidas, dos projetos bem feitos, do esforço. Mas há lances do destino, que interrompem as iniciativas individuais - lances de sorte e azar. O asilamento, assim, resulta de múltiplos fatores, dos quais uma parte significativa está alheia às motivações de cada um.

As fantasias não implicam necessariamente em "mentiras" ou "falsidades", dado que nem todas as invenções são deliberadas. A imaginação é parte constitutiva dos jogos de memória: toda lembrança é organizada através de relações imaginárias entre eventos, personagens e espaços sociais. A duração, diria Gaston Bachelard (1994), é uma dialética de lembranças e contra-lembranças. O resultado desse processo, que nunca cessa, são as imagens, forma e conteúdo da memória, que

${ }^{6}$ Intérprete e compositor gaúcho, notável por suas canções tradicionalistas.

${ }^{7}$ Tangerina. 
são experimentadas subjetivamente, mas cuja constituição é coletiva e compartilhada.

No Asilo Padre Cacique, a reinvenção de trajetórias sociais parecia cumprir a importante função de definir dinamicamente a identidade através da narrativa. Nesse sentido, os códigos de distinção/identificação configuravam critérios de verossimilhança ou mesmo as categorias de acusação. "Mentira" e "fantasia" são termos que classificavam as histórias aparentemente falsas, que não correspondiam aos códigos socialmente estabelecidos. "Mentir" era o verbo aplicado a alguém que queria "levar vantagem", criando referências não condizentes com a condição da velhice ou com o que é comunicado pelo corpo. "Fantasiar" definia alguma história incoerente contada por alguém cujo corpo comunicava a senilidade. Nesse último caso, a invenção poderia ser considerada inocente, como o fruto de uma mente que "está falhando".

A hierarquia de idades foi outro importante fator das relações identitárias no Asilo. Um homem de 80 ou 90 anos precisava ser respeitado apesar de suas fantasias e de suas incontinências fisiológicas ou emocionais. O que não significa dizer que códigos eram suspensos, uma vez que a estigmatização continuava em jogo. Mas há que se tolerar os mais velhos - já que é o destino inevitável de todos os asilados. Alguns, como João, preferiam a morte rápida à senilidade. Era generalizada a aspiração de viver o máximo de dias, meses e anos, desde que com saúde, sem a ocorrência de uma isquemia ou um infarto. Ir para a enfermaria significava, "trazer incomodação pros outros", como disse João certa vez.

A tolerância com os mais velhos ou com os debilitados tinha seu limite, revelado nas trocas humorísticas. As piadas, de mau gosto ou não, reforçam as distinções no Asilo - distingue-se os senis e afirma-se que a perda da consciência está, no presente, ainda distante. A ridicularização também é uma maneira de minar posições de prestígio: ser alvo de uma piada significa ser deslocado temporariamente na hierarquia social. O estudante, o voluntário ou o funcionário poderia ser "colocado para baixo" por não saber interpretar os códigos da cultura asilar. Assim, invertiam-se as relações de força e um velho podia tirar partido da ocasião para conquistar uma "vitória num espaço maravilhoso, utópico.” (DE CERTEAU, 1996, p. 85). 
A velhice masculina no asilo também se enveredou pelo sentimento de honra, estreitamente ligado à afirmação e aplicação dos códigos e das normas. Entre os homens, os conflitos foram fortemente pautados por acusações de desrespeito aos mais velhos, voluntários, funcionários e às regras de conduta estabelecidas pela instituição. Uma discussão sobre se as portas e janelas devem ou não permanecer fechadas resultou no remanejamento de um dos antagonistas, mesmo com as tentativas de reconciliação mediadas pelo serviço social ou pela direção do asilo. Muitas vezes motivos banais trouxeram à tona distinções de classe, de gosto ou estilo de vida, tornando a convivência inviável e definindo a necessidade de um distanciamento espacial.

\section{Os Ritmos Asilares}

A atenção detalhada aos ritmos cotidianos tornou-se a chave para a compreensão das diversas camadas de sentido presentes no Asilo Padre Cacique. Partindo da premissa de que nem o tempo ou o espaço são meios homogêneos onde os fenômenos se desenrolam, mas termos definidos relacionalmente segundo as práticas sociais, percebeu-se que os ritmos do processo de envelhecer no asilo assumem diferentes formas e caracteres dependendo das ocupações, das distrações, dos descansos, dos hábitos, das irregularidades e dos intervalos da vida cotidiana. Porém, os ritmos asilares não são facilmente transmitidos através de conceitos. O uso da fotografia foi fundamental nesse sentido ${ }^{8}$, garantindo um olhar paciente, que se permite levar pela duração da experiência de envelhecer.

Em cada lugar e momento, ritmos diferentes se impõem: eles estão intimamente relacionados às experiências de habitação dos espaços. O tempo da instituição engloba os tempos individuais e é composto por eles. No refeitório do Asilo Padre Cacique, local privilegiado da sociabilidade, a sineta convidava à reunião. Por vezes, havia festas, apresentações e visitas, que irrompiam os ritmos habituais da alimentação. Um "aprofundamento dos instantes" (BACHELARD, 1994) tinha lugar. Os idosos passavam a se relacionar afetivamente com o espetáculo, sem deixar as mesas imediatamente e permanecendo atentos ao desenrolar da trama.

8 Algumas das imagens podem ser acessadas em: http://lucasgraeff.googlepages.com 
O limite entre o corredor e o jardim, abaixo de um arco, resguardou muitos instantes de intimidade, sempre silenciosos e solitários. Rui, em sua cadeira de rodas, cochilou várias tardes ali durante o inverno, aproveitando o calor do sol em frente à entrada do refeitório. Novamente, para quem olha de fora, esse repouso remetia a imagens da velhice desamparada. Mas foi preciso reconhecer que a solidão e o silêncio costumam andar juntos com a intimidade, proporcionando o repouso necessário à habitação de um espaço privado. E, nesse repouso, constituía-se uma certa autonomia. Era um silêncio a ser interpretado em sua positividade, desde que percebido enquanto um mistério íntimo, muitas vezes carregado de valor social.

$\mathrm{Na}$ ala feminina, a ocupação dos corredores oscilou ao sabor das estações. O frio, que derruba, esvazia sofás e cadeiras, fazia com que os ritmos ficassem mais pesados. Os que se arriscavam a caminhar apesar dos ventos, o faziam vagarosamente, arrastando os pés. Nos quartos, foi preciso saber entrar. Tratava-se, antes de tudo, de um espaço doméstico - territórios privados, "onde todo visitante é um intruso, a menos que tenha sido explícita e livremente convidado a entrar." (DE CERTEAU, 1997, p. 203). Ainda que convidado, precisei tomar consciência do "meu lugar". Não era possível, evidentemente, acomodarse em qualquer canto, sobre a cama ou sobre uma cadeira. Da mesma maneira como era preciso reconhecer os tempos próprios para visitas e conversas: o quarto, enquanto espaço coletivo, englobava as privacidades. Outros silêncios se instalavam ali, longe de olhares indiscretos e acusadores.

Sendo bem-vindo, tornou-se possível perceber os esforços de habitação presentes em cada "cantinho": as preferências e exclusões de objetos, as formas de ordenação, a disposição do criado-mudo e da cadeira, as fontes de luz, os espelhos, os livros e jornais abertos; enfim, as harmonias e discrepâncias próprias da função de habitar. Evidentemente, essas pequenas coleções de objetos, roupas e utensílios representavam o universo singular de seus donos.

Um armário cadeado, além de remeter ao medo de furtos, também pôde servir como uma tentativa de estocar lembranças - uma síntese entre vontade e memória, como diria Bachelard (2000). Objetos socialmente relevantes, quando secretamente organizados, servem como âncoras da memória e da identidade. O armário é referência primeira 
para quem vem morar no Asilo Padre Cacique: em torno dele gira o cotidiano e dentro dele estão resguardados os elementos mínimos da intimidade. Um armário que suscita devaneios curtos, solicitados pelos detalhes das coisas insignificantes - objetos empoeirados, arranhados, gastos; fotos perdidas, exiladas dos antigos álbuns de família; utensílios ainda úteis, como a escova de cabelo ou de dente, a espuma de barbear ou os óculos velhos, por vezes amarrados com um esparadrapo.

A análise empreendida por Letícia Ferreira (1995) ressaltou as rupturas com os ritmos domésticos acarretados pela entrada do idoso em um pensionato. Apesar do contraste entre o "mundo do lar" e o "mundo do pensionato", era possível restaurar a identidade social através de miniaturas afetivas, que contribuíam também para reproduzir os ritmos e hábitos consolidados com o tempo. Lar e pensionato, portanto, eram análogos e revelavam importantes marcos identitários. No Asilo Padre Cacique, ainda que a pesquisa realizada não tenha abrangido os lares anteriores dos informantes, os armários também se revelaram como analogias. Ou melhor: como alegorias das preferências e estilos de vida de seus donos.

Curiosamente, os armários também se transformavam, confessando as aspirações de momento e as maneiras de reinventar as trajetórias de seus ocupantes. No ritmo do cotidiano, um armário nunca é o mesmo armário. As dádivas, as premiações dos jogos, a escolha de roupas, as compras, as garimpagens no subsolo do asilo, onde os restos e rastros são depositados: todo objeto apropriado é, simultaneamente, um indicador e um transformador das preferências pessoais no presente. Por fim, os espaços da intimidade puderam abrigar o corpo doente, servindo-lhe de refúgio restaurador - "na cama dá para fazer aquele recuo estratégico, ficar na tua, te recuperar", como relatou Azevedo.

$\mathrm{Na}$ ala masculina, circulavam as "mentiras" e "fantasias". Os contadores de história e os piadistas aproveitavam a atenção do visitante para contar vantagens e se distinguir. Nesses momentos lúdicos, o tempo oscilava entre as palavras e os pigarros. E parava repentinamente quando chegava um morador estigmatizado, senil. Instantes de constrangimento frente a um futuro possível, a um espelho trêmulo. Nos grandes quartos da ala masculina, nem sempre foi necessário um convite para entrar, mesmo porque a maior parte das camas permanecia desabitada durante o dia. Porém, para conhecer o armário de cada 
pessoa, o ideal foi tomar parte nos tempos vividos nos corredores e só depois propor ou ser convidado a conhecer os espaços da intimidade.

No Asilo Padre Cacique, os aspectos mais dramáticos se revelaram na enfermaria. É lá que saltaram aos olhos as imprevisibilidades do cotidiano, onde o núcleo organizador dos códigos de distinção/identificação - o temor da senilidade - apresenta seu caráter concreto. Lá, o tempo apresentou sua faceta inexorável: as mortes e doenças indicam que os ritmos sucessivos do corpo não durarão para sempre, transformando-se até atingir a imobilidade. A construção social do luto na cultura asilar passa, assim, pelo testemunho sistemático da finitude. São tais vicissitudes dramáticas da vida que estabelecem os limites da produção e interpretação de sentidos do envelhecer.

\section{As Narrativas e Produção de Sentido}

É uma tarefa irrealizável a tentativa de recompor os ritmos das narrativas no papel. Perdem-se as performances, com seus gestos, suspiros, hesitações e silêncios, e ficam as grandes divisões - "no tempo do Getúlio", "na minha época" - mas o esforço mesmo de totalidade realizado pelo pensamento acaba se perdendo. O ritmo da leitura não é o mesmo da escrita, que não é o do ouvinte, que não é o do narrador. Ordená-los e compô-los é um desafio sistemático de interpretação e compreensão. É preciso buscar outros meios de significação, compor imagens, sons, música e escrita ${ }^{9}$. Ao final, sugere-se que todos os ritmos transcritos não traduzem, de fato, aqueles da experiência de envelhecer no Asilo. Servem, porém, como recursos múltiplos à imaginação.

A dinâmica interativa das entrevistas coloca o velho em posição de prestígio social, o que implica na consciência da responsabilidade de transmitir valores e perspectivas sobre o mundo e sobre o asilo: o velho recupera, assim, sua condição de pertencimento afetivo à comunidade de lembrança. Nesses termos, a narração das trajetórias sociais não apenas resulta no acesso às camadas da memória coletiva, mas agrega densidade a elas. A percepção de continuidade social foi fortalecida - "o meu tempo passou, mas tu tá na luta ainda", como confessou Pe-

A dissertação de mestrado que resultou da pesquisa etnográfica contém um capitulo em vídeo, dedicado ao estudo dos armários, além de um conjunto de 40 fotografias que procuraram restaurar imaginariamente os diversos espaços do Asilo Padre Cacique. Pode ser consultada em: na Biblioteca Setorial de Ciências Sociais e Humanidades da UFRGS. 
dro, insistindo que era preciso retomar uma relação com um político local para ajudar na divulgação do trabalho antropológico.

Nas palavras de Pierre Bourdieu (2001), a criação de sentido pela biografia ou narrativa é sempre um "artefato". Porém, nesse artefato depositam-se conteúdos sociais que definem as condições da transmissão da experiência. Lembrar é um processo que segue demarcações socialmente compartilhadas - "na sociedade estão todas as indicações necessárias para reconstruir [ . . . ] as imagens dos acontecimentos passados." (HALBWACHS, 1990, p. 77). Ao recuperar as singularidades do processo de envelhecer no asilo, os artefatos biográficos também revelaram os caminhos e descaminhos da memória coletiva e a operação de unificação, dada pelo pensamento, que articula diferentes ações e circunstâncias segundo ordens socialmente compartilhadas.

Recuperar as trajetórias sociais e o cotidiano asilar através do trabalho da memória teve como finalidade a proposição de instantes privilegiados, onde os idosos puderam reconstituir as durações de seus tempos vividos através das narrativas. Com seus silêncios, esquecimentos e performances, o narrador procura salvar os sentidos da experiência (BENJAMIN, 1996), tecendo incessantemente um conhecimento sobre si mesmos e sobre o mundo. Uma situação de reciprocidade, de interlocução, é fundamental para a transmissão das formas de existência social e para o enquadramento social das lembranças: os relatos são pensados cuidadosamente pelo narrador de acordo com as variações de entusiasmo e interesse do ouvinte. Reconstituir a duração é ultrapassar as ambigüidades, as lacunas e os esquecimentos que fragmentam a identidade social, transformando a imagem de si através do trabalho da memória.

Pedro narrou momentos excepcionais como se constituíssem uma epopéia, exaltando suas ações, os infortúnios e as peripécias de ocasião. Sua habilidade poética resulta em uma experiência de continuidade: ao construir um personagem, ele organizou sua identidade e procurou assegurar a sua autoridade para dar conselhos sobre papéis sociais e estilos de vida no mundo da velhice.

Ao manipular seu estigma, brincando com as palavras, cantando e dançando, Marieta configurou uma identidade narrativa singular, lúdica. Sem abrir mão de uma tática cotidiana fundamental - a afetividade e sedução através das suas músicas - ela procurou manter seu projeto 
de retornar à sua casa e à comunidade.

Azevedo elegeu o subsolo do Asilo como seu espaço afetivo, atualizando sua identidade de "parceiro da solidão", músico e companheiro fraternal dos necessitados. Ele reconstruiu sua história e, através dela, procurou justificar suas interpretações sobre a cultura asilar, tornando-se um cronista do Asilo. Ele foi um dos poucos moradores a narrar seu ciclo de vida, o que lhe inscreveu quase naturalmente em uma cultura de camadas médias (VELHO, 2004), geralmente ausente das representações sobre a velhice pobre e asilada no Brasil.

$\mathrm{Na}$ sala de visitas, Luduvica realizava a mediação entre visitantes, voluntários e moradores do Asilo, agenciando a sociabilidade e o lazer. Em sua narrativa, ela utilizou categorias da Terceira Idade para interpretar os colegas de instituição. Cotidianamente, posicionouse como porta-voz das atividades lúdicas e colaborou ativamente no cuidado com os "velhinhos", distinguindo-se deles.

Através da literatura, Rui deu continuidade a um estilo de vida de formação cultural, ao qual não teria acesso não fosse a sua destreza de livreiro. Comercializar livros foi uma oportunidade de circular entre grupos sociais. Ele organizou uma narrativa heróica, mesclando uma série de táticas cotidianas para vender livros proibidos durante a ditadura militar. Ele enfatizou seu gosto por filmes, relacionando-o a lembranças de sua infância e juventude.

Mesclando as lembranças das modificações espaciais e as das relações afetivas, Lídia testemunhou mudanças significativas no Asilo Padre Cacique. Apesar da perda gradativa da visão, ela ainda foi capaz de recuperar imagens e lembranças que contrastavam com a condição presente do Asilo. Em seu quarto, ninguém podia lhe faltar com a honra: as relações afetivas mantidas ao longo dos anos lhe asseguravam a autoridade pelo afeto. Ela demonstra que fez por merecer o respeito e o reconhecimento de todos que vivem o cotidiano asilar.

Ao favorecer a tessitura de sentidos, as entrevistas não-diretivas sobre as relações entre a trajetória social e o cotidiano asilar acabaram por formalizar uma "ritmanálise" (BACHELARD, 1994). Durante os jogos de memória, os velhos enquadraram pelo pensamento a ação real do tempo - que marca inexoravelmente o corpo - através da riqueza das paisagens afetivas, das coincidências vividas e das peripécias. Prudentemente, criou-se uma condição de repouso, capaz de extravasar os 
ritmos cotidianos e de assegurar uma posição diferenciada, a partir da qual puderam, de fato, afirmar sua inteligência narrativa.

\section{Conclusão}

Contextualizar os moradores do Asilo Padre Cacique no quadro de seus dramas e de seu cotidiano coloca em questão a construção social de algumas representações compartilhadas sobre o asilamento no Brasil. Uma delas baseia-se na premissa da "mortificação do eu" causado pelo caráter totalizador de qualquer instituição voltada para a velhice. Quando Erving Goffman (1974) formulou sua teoria, as sociedades disciplinares ainda estavam em seu apogeu (DELEUZE, 2000) e, de fato, o indivíduo não cessava de passar de um espaço fechado para outro - da família para a escola; da escola para a fábrica; da fábrica para o hospital ou, eventualmente, a prisão ou o asilo.

As instituições totais eram projetos de confinamento por excelência, com o objetivo de concentrar no espaço, ordenar no tempo, centralizar a autoridade e racionalizar os esforços. Na contemporaneidade, porém, essas mesmas sociedades disciplinares se transformaram, tornando-se "reflexivas" ou "complexas"10: os atores sociais se colocam em experiências diversificadas, cruzando ethos e visões de mundo contrastantes, demarcando, assim, projetos e trajetórias sociais que são significadas como singulares (VELHO, 2004). É nesse contexto ideológico que a premissa da "mortificação do eu" deve ser pensada criticamente.

Dada a política de abertura que estava sendo aplicada pela direção, o Asilo Padre Cacique não pôde ser definido facilmente como uma "instituição total". O controle social aplicado nesse micro-universo simbólico enfrentou resistências e sofreu mudanças, como nos critérios de seleção e nos horários de visitas, passando pelo convite à participação de familiares e voluntários no dia-a-dia e nas festas do Asilo, até as pequenas modificações nos quartos, cada vez menores, privados, proporcionando espaços de intimidade.

\footnotetext{
${ }^{10}$ Sem entrar nos méritos da longa e importante discussão, que vem ocupando cientistas sociais e historiadores (GIDDENS, 1994; KUPER, 1998; VELHO, 2004; entre outros), sobre definições de centro x periferia, sociedades complexas x simples etc., o dado fundamental aqui é a própria transformação.
} 
O Asilo Padre Cacique faz parte de um conjunto de reflexões e ações voltadas para a velhice e sua política não pode ser compreendida como um fato isolado. No mesmo período em que vinha se abrindo, circulavam na mídia impressa e televisiva e nos meios acadêmicos e profissionais voltados ao envelhecimento uma série de idéias-valor que configuram o discurso da Terceira Idade. Nessa época, também foi promulgado o Estatuto do Idoso no Brasil, que vem servindo de instrumento de reivindicações políticas e para o próprio Estado, que se apóia na Lei para fiscalizar as instituições filantrópicas, religiosas e privadas de amparo à velhice e à Terceira Idade. Portanto, se a política de abertura do Asilo pode ser considerada pioneira, ela é absolutamente coerente com o contexto sócio-político em que estava inserida.

Desde tais considerações, segue-se que o próprio caráter das instituições voltadas para a velhice está sendo redefinido. Frente às mudanças, novas premissas e conceitos precisam ganhar espaço para que outras dimensões da experiência de envelhecer no asilo possam ser interpretadas. Os tempos vividos nos espaços sociais e as memórias narradas são fundamentais para contrapor criticamente a premissa da mortificação do eu. Habitar os lugares, reinventar ou "fantasiar" a trajetória social e estabelecer novas relações de sociabilidade configuraram situações singulares, mais complexas que essa "brincadeira ritual de ter um eu" da teoria interacionista (GEERTZ, 1989). Prefiro falar de um movimento de afirmação de diferenças do que um simples jogo entre aquilo que é imposto pela institucionalização e o que é negociado estrategicamente pelos atores.

A teoria das instituições totais deve ser assumida enquanto tal: como uma ferramenta conceitual que contribui para compreender o drama do asilamento e para criticar o caráter totalitário de determinadas gestões. Mas há outros aspectos da cultura asilar, muitos deles também dramáticos, que não podem ser interpretados ou explicados exclusivamente através dessa teoria - as carreiras da velhice, que são maneiras de viver e de ressignificar a condição de asilamento; os ritmos cotidianos, que conformam temporalidades próprias na cultura asilar; e as narrativas dos velhos, sujeitos de experiências singulares, que realizam um esforço sistemático de dar sentido às suas experiências.

As imagens da velhice institucionalizada, enquanto construções sociais, também vêm se transformando. As descrições etnográficas 
apresentadas aqui não devem servir como negação de fatos concretos ligados a essas imagens, como a exclusão social, a pauperização e o abandono familiar. Seu objetivo foi apresentar o trabalho que os moradores do Asilo Padre Cacique realizaram para ressignificar suas trajetórias e identidades sociais e para afirmar a dignidade de suas condições de vida. Esse esforço só é visível quando o pesquisador aceita participar, ainda que temporariamente, do mundo da velhice e de suas camadas de sentido.

Foi fundamental suportar os "ritmos da eternidade" do Asilo, com suas raras cadeias de ação e tragédias cotidianas ${ }^{11}$. A transformação epistemológica propiciada pela etnografia, sempre fundada em categorias e conceitos antropológicos, renovou a cadência desses ritmos. Junto com o tempo, as imagens se transformaram: percebi as redes sociais aparentemente inexistentes e compreendi a dimensão social dos conflitos e a diversidade das experiências vividas no interior da instituição. Assim, a heterogeneidade da questão asilar se impôs, convidandome a pensar. Fica o mesmo convite para o leitor.

\title{
TOTAL INSTITUTIONS AND THE THE LONG TERM INSTI- TUTIONS FOR AGED PEOPLE: an comprehensive approach
}

\begin{abstract}
This anthropological study on aging in the context of a long term care institution is the result of an ethnographic research developed between August 2004 and December 2005, at the Asilo Padre Cacique, in Porto Alegre - RS, Brasil. It reviews the Theory of Total Institutions by analyzing the conditions of life and the process of aging of the institution's residents, with objective to know their practices, interpret their experience of lived time and understand how these aged persons think their lives in the daily life of the institution.
\end{abstract}

Keywords: Institutions. Daily Life. Old Age.

\footnotetext{
${ }^{11}$ Há, de fato, tragédia maior que ser "derrubado" pelo próprio corpo enfraquecido?
} 


\section{REFERÊNCIAS}

BACHELARD, Gaston. A Dialética da Duração. 2. ed. São Paulo: Ática, 1994.

BACHELARD, Gaston. A Poética do Espaço. São Paulo: Ática, 2000.

BENJAMIN, Walter. Magia, Técnica, Arte e Politica: ensaios sobre literatura e história da cultura. São Paulo: Brasiliense, 1996.

BOURDIEU, Pierre. Razões Práticas. 3. ed. Campinas: Papirus, 2001.

DEBERT, Guita Grin. A Reinvenção da Velhice: socialização e processos de reprivatização do envelhecimento. São Paulo: EDUSP, 1999.

DE CERTEAU, Michel. A Invenção do Cotidiano: artes de fazer. 2. ed. Petrópolis: Vozes, 1996.

DE CERTEAU, Michel. A Invenção do Cotidiano: morar, cozinhar. 2. ed. Petrópolis: Vozes, 1997.

DELEUZE, Gilles. Conversações. Rio de Janeiro: Ed. 34, 2000.

DILTHEY, Wilhelm. Critique de la raison historique. Paris: Le Cerf, 1992.

ELIAS, Norbert. A Sociedade de Corte. Rio de Janeiro: Jorge Zahar, 1994.

FERREIRA, Maria Letícia Mazzucchi. Folheando o Passado: estudo antropológico sobre memória e identidade social na velhice. 1995. 215 f. Dissertação (Mestrado) - Universidade Federal do Rio Grande do Sul. Instituto de Filosofia e Ciências Humanas. Programa de Pós-Graduação em Antropologia Social, Porto Alegre, 1995.

GADAMER, Hans-Georg. Verdade e Método. Petrópolis: Vozes, 1997.

GEERTZ, Clifford. A Interpretação das Culturas. Rio de Janeiro: LTC, 1989. 
GIDDENS, Anthony. Living in a Post-Traditional Society. In: BECK, Ulrich; GIDDENS, Anthony; LASH, Scott. Reflexive Modernization. Cambridge: Polity Press, 1994. P. 56-109.

GOFFMAN, Erving. Manicômios, Prisões e Conventos. São Paulo: Perspectiva, 1974.

GRAEFF, Lucas. $O$ "Mundo da Velhice" e a Cultura Asilar: estudo antropológico sobre memória social e cotidiano de velhos no Asilo Padre Cacique, em Porto Alegre. 2005. 172 f. Dissertação (Mestrado em Antropologia)- Instituto de Filosofia e Ciências Humanas, Universidade Federal do Rio Grande do

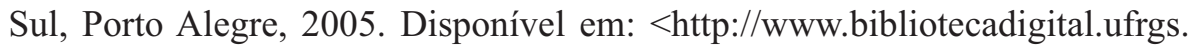
br/da.php?nrb=000515601\&loc $=2006 \& l=44 b d 702768 b 2$ fa32 $>$. Acesso em: 12 mar. 2007.

HALBWACHS, Maurice. Memória Coletiva. São Paulo: Vértice, 1990.

KUPER, Adam. Among the Anthropologists: history and context in Anthropology. London: Athlone Press, 1998.

LE BRETON, David. Anthropologie du corps et modernité. 4. ed. Paris: PUF, 2005.

OLIVEIRA, Roberto Cardoso de. Sobre o Pensamento Antropológico. Rio de Janeiro: Tempo Brasileiro, 2003.

SAHLINS, Marshall. Ilhas de História. Rio de Janeiro: Zahar, 2004.

TURNER, Victor. From Ritual to Theatre: the human seriousness of play. New York: PAJ, 1982.

VELHO, Gilberto. Individualismo e Cultura: notas para uma antropologia da sociedade contemporânea. 7. ed. Rio de Janeiro: Zahar, 2004.

Recebido em: 18.01.2007

$1^{a}$ reformulação: 14.03 .2007

Aceite final: 13.09.2007 